\title{
Two new species of the genus Melixanthus Suffrian (Coleoptera, Chrysomelidae, Cryptocephalinae) from China
}

\author{
Wen-Yuan Duan ${ }^{1,2}$, Feng-Yan Wang ${ }^{1,2}$, Hong-Zhang Zhou ${ }^{1,2}$ \\ I Key Laboratory of Zoological Systematics and Evolution, Institute of Zoology, Chinese Academy of Sciences, 1 \\ Beichen West Rd., Chaoyang District, Beijing 100101, China 2 University of the Chinese Academy of Sciences, \\ 19 A Yuquan Rd., Shijingshan District, Beijing 100049, China
}

Corresponding author: Hong-Zhang Zhou (zhouhz@ioz.ac.cn)

Academic editor: Astrid Eben | Received 16 June 2021 | Accepted 10 August 2021 | Published 17 September 2021

http://zoobank.org/594190F9-8E0D-4B94-93EE-731612FB209A

Citation: Duan W-Y, Wang F-Y, Zhou H-Z (2021) Two new species of the genus Melixanthus Suffrian (Coleoptera, Chrysomelidae, Cryptocephalinae) from China. ZooKeys 1060: 111-123. https://doi.org/10.3897/zookeys.1060.70203

\begin{abstract}
Two new species of the genus Melixanthus Suffrian, 1854 are described from China: M. menglaensis Duan, Wang \& Zhou, sp. nov. from Yunnan (also in Vietnam, Tonkin) and M. similibimaculicollis Duan, Wang \& Zhou, sp. nov. from Yunnan. Another species, M. rufiventris Pic, 1926, is reported for the first time in China. High-quality color images and line drawings of adult habitus, aedeagus, and other important structures are provided for all three species. The types of the new species are deposited in the collection of Institute of Zoology, Chinese Academy of Sciences (IZ-CAS).
\end{abstract}

\section{Keywords}

Cryptocephalini, distributional records, leaf beetles, new species

\section{Introduction}

The leaf beetle genus Melixanthus Suffrian, 1854 (Chrysomelidae, Cryptocephalini) is mainly distributed in the Oriental region and includes approximately 60 species until now; of these, 11 species are known to occur in China (Gressitt and Kimoto 1961; Tan 
et al. 1980; Tan 1988; Tan and Pu 1992; Lopatin 2005; Schöller et al. 2010). This genus was erected very early on as valid genus-level taxon and can be diagnosed by the following characteristics: antennae rather short, usually reaching humeral region of elytra; apical six segments broadened and flatted, about 1.2-2.2 times as long as wide; claws of all legs usually toothed or thickened basally. Not all Melixanthus species readily show the character of claws with or without teeth, and at least a few of species are not easily included in or excluded from this genus. This has challenged taxonomists studying this group.

The Chinese fauna of the genus was studied by including in a comprehensive study on the family Chrysomelidae (e.g., Chûjô 1954; Gressitt and Kimoto 1961; Tan et al. 1980; Schöller et al. 2010). Kimoto and Gressitt (1981) studied the chrysomelid fauna of Thailand, Cambodia, Laos, and Vietnam (countries near China), and thus their publication is important in identifying the Chinese species. The most recent and comprehensive study of Melixanthus, having excellent species revisions and key to species, was published by Medvedev (2012).

Our present study reports new findings, including the description of two new species of Melixanthus from China.

\section{Materials and methods}

Dried specimens were relaxed in hot distilled water at $80{ }^{\circ} \mathrm{C}$ for about $2 \mathrm{~h}$ to soften the body and ease dissection. The abdomen was separated with insect pins from the rest of the body, soaked in $10 \% \mathrm{KOH}$ solution and then in a hot water bath for 15 min to advance the process. After this, specimens were transferred in distilled water to rinse the residual $\mathrm{KOH}$ solution off and stop the bleaching process. Afterwards, the aedeagus, spermatheca and rectal sclerites were prepared. The dissected parts were placed into glycerin for observation and measurement with an apochromatic stereomicroscope Zeiss SteREO V12. Color photographs of the adults and genitalia were captured with an Axio Zoom V16 fluorescence stereo zoom microscope and photomontage was performed in Zen 2012 (blue edition) imaging software. Adobe Photoshop CS6 was used in digital post-processing of the color images, and Adobe Illustrator 2020 was used to make the line drawings.

Materials used in this study are from the collection: IZ-CAS (Institute of Zoology, Chinese Academy of Sciences, Beijing, China).

Measurements are average values calculated from the values of at least five specimens, or all available specimens in case less than five specimens were available. The following abbreviations are used in the text to indicate the measurements of the specimens:

BL body length (length from the apex of pronotum to the apex of elytra in dorsal view);

BW body width (distance between the humeri, maximal body width);

HL head length (length from occiput to the front apex of mandibles);

HW head width (distance between the outer margin of eyes in frontal view, maximal head width); 
PL pronotal length (length from the basal angle to anterior margin, maximal longitudinal length of pronotum);

PW pronotal width (distance of the widest portion of the pronotum);

EL elytral length (length of the maximal elytral length in dorsal view);

AL aedeagus length (length from the apex of aedeagus to the basal margin, maximal aedeagus length);

AW aedeagus width (the maximal width of aedeagus);

SL spermathecal length (length of the maximal spermathecal length, without duct).

\section{Taxonomy}

\section{Genus Melixanthus Suffrian, 1854}

Suffrian 1854: 8; Chapuis 1874: 175; Jacoby 1908: 267; Clavareau 1913: 197; Gressitt 1942: 330 353; Chûjô 1954: 187; Gressitt and Kimoto 1961: 169; Tan et al. 1981: 174; Kimoto and Gressitt 1981: 329; Schöller et al. 2010: 606; Medvedev 2012: 162.

Type species. Melixanthus intermedius Suffrian, 1854.

Synonym. Suffrianus Weise, 1895: 58. Type species: Cryptocephalus pumilio Suffrian, 1854.

Melixanthus menglaensis Duan, Wang \& Zhou, sp. nov.

http://zoobank.org/CDAC18DD-5DF4-4115-9CCA-42553FB9E0C2

Figures $1-5$

Type locality. China: Yunnan Province: Mengla.

Type material examined. Holotype: male, CHINA: Yunnan Province: Mengla, Menglun, II-IV.1979, coll. unknown (IZ-CAS). Paratypes: China: Yunnan Province: 4 males, 2 females, same data as holotype (IZ-CAS); 1 female, Xishuangbanna, Gannanba, 14.III.1957, coll. Shuyong Wang (IZ-CAS); 1 female, Xishuangbanna, Gannanba, 21.III.1957, coll. Shuyong Wang (IZ-CAS); 1 female, Cheli, 9. IV.1955, coll. Fengyu Xue (IZ-CAS). Vietnam: Tonkin: 4 males, 3 females, III.1937, coll. unknown (IZ-CAS).

Measurements. $\mathrm{BL}=3.25-3.60 \mathrm{~mm}, \mathrm{BW}=2.02-2.24 \mathrm{~mm}, \mathrm{HL}=0.91 \mathrm{~mm}$, $\mathrm{HW}=0.91 \mathrm{~mm}, \mathrm{PL}=1.08 \mathrm{~mm}, \mathrm{PW}=2.02 \mathrm{~mm}, \mathrm{EL}=2.00 \mathrm{~mm}, \mathrm{AL}=0.87 \mathrm{~mm}$, $\mathrm{AW}=0.27 \mathrm{~mm}, \mathrm{SL}=0.41 \mathrm{~mm}$.

Description. Body (Fig. 3A-D) elongate, almost cylindrical, rounded anteriorly. Head (Fig. 3E) yellow, vertex with a darkish brown M-shaped marking; antennae (Fig. 3F) with basal 5 segments yellowish brown, terminal 6 segments reddish brown; clypeus yellow; labrum yellowish brown; mandibles darkish brown. Pronotum yellow, 

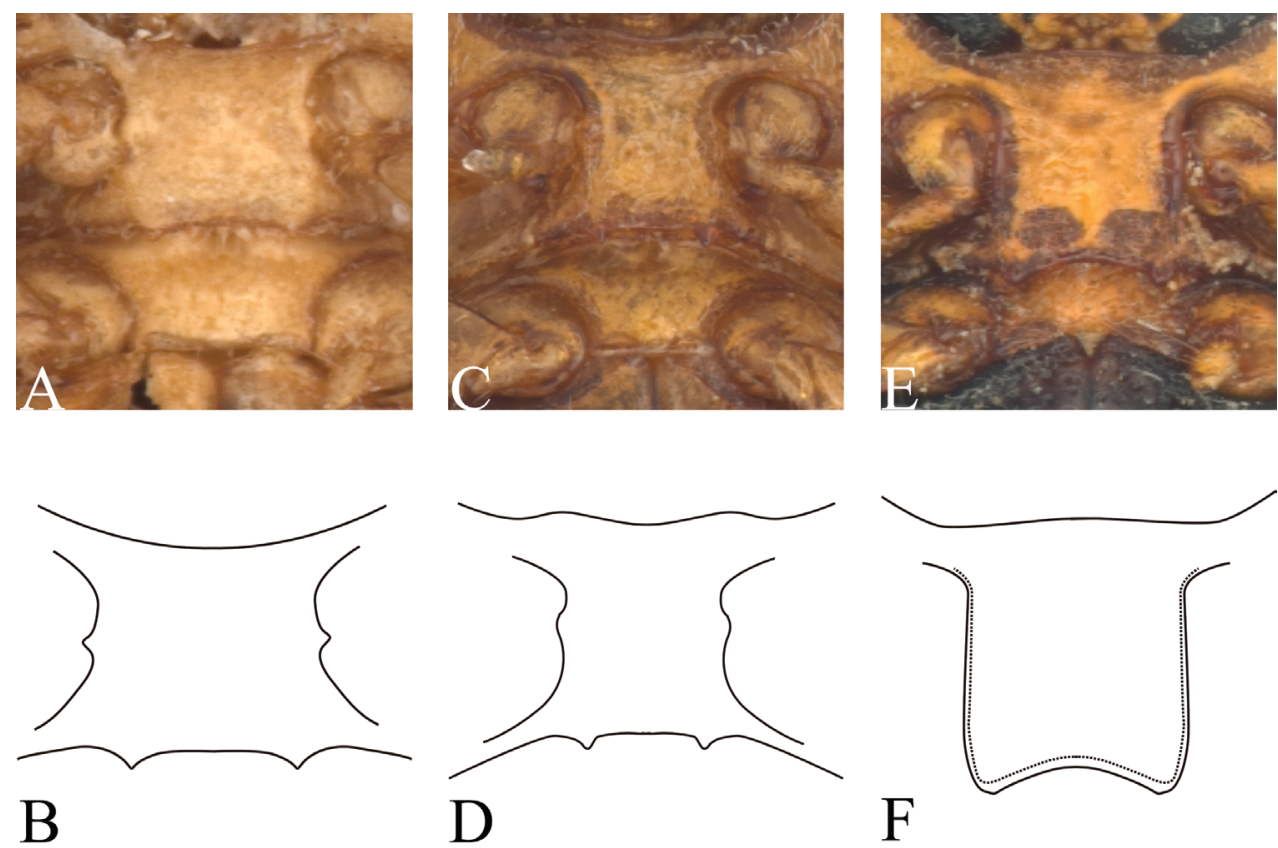

B

$\mathrm{D}$

Figure I. Melixanthus prosternum A, B $M$. menglaensis Duan, Wang \& Zhou, sp. nov. C, D M. similibimaculicollis Duan, Wang \& Zhou, sp. nov. E, F M. bimaculicollis Baly, 1865.

with two pitchy brown subtriangular markings along anterior margin. Scutellum yellow and margins black. Elytra pitchy brown, with a yellowish-brown band in middle region, covering about $1 / 2$ of whole region; margins pitchy brown. Sometimes entirely yellow, only margins pitchy brown. Ventral surface yellow, metasternum with a rectangular black marking. Legs and pygidium all yellow.

Head (Fig. 3E) densely and coarsely punctate, flattened on midline, longitudinally impressed on frons and vertex. Eyes kidney-shaped, deeply emarginated; antennal insertions a little more widely separated than superior eye-lobes. Clypeus sparsely punctate, strongly arcuate on anterior margin. Antennae (Fig. 3F) with sparsely long hair, short and slightly broad, reaching humeral tubercle; $1^{\text {st }}$ segment clubbed; $2^{\text {nd }}$ oblong, about half as long as $1^{\text {st }} ; 3^{\text {rd }}-5^{\text {th }}$ thin, about equal in length, longer than $2^{\text {nd }} ; 6$ apical segments moderately thickened, about 2.0-2.2 times as long as wide, last segment pointed apically.

Pronotum (Fig. 3A-D) 1.8 times as wide as long, moderately narrowed and rounded anteriorly; surface strongly convex, impunctate and shining. Scutellum triangular, nearly as long as wide, surface smooth, shining.

Elytron (Fig. 3A-D) parallel-sides, apical margin slightly straight, 2.0 times as long as wide, humeri prominent and glabrous. Disc with regular rows of fine punctures, partly confused near apical slope; interspaces without punctures; epipleurae slightly obliquely placed and seen in lateral view.

Ventral side (Fig. 3G) partly clothed with pubescence. Prosternum (Fig. 1A, B) square, anterior margin slightly concave; basal margin nearly straight, and drawn 

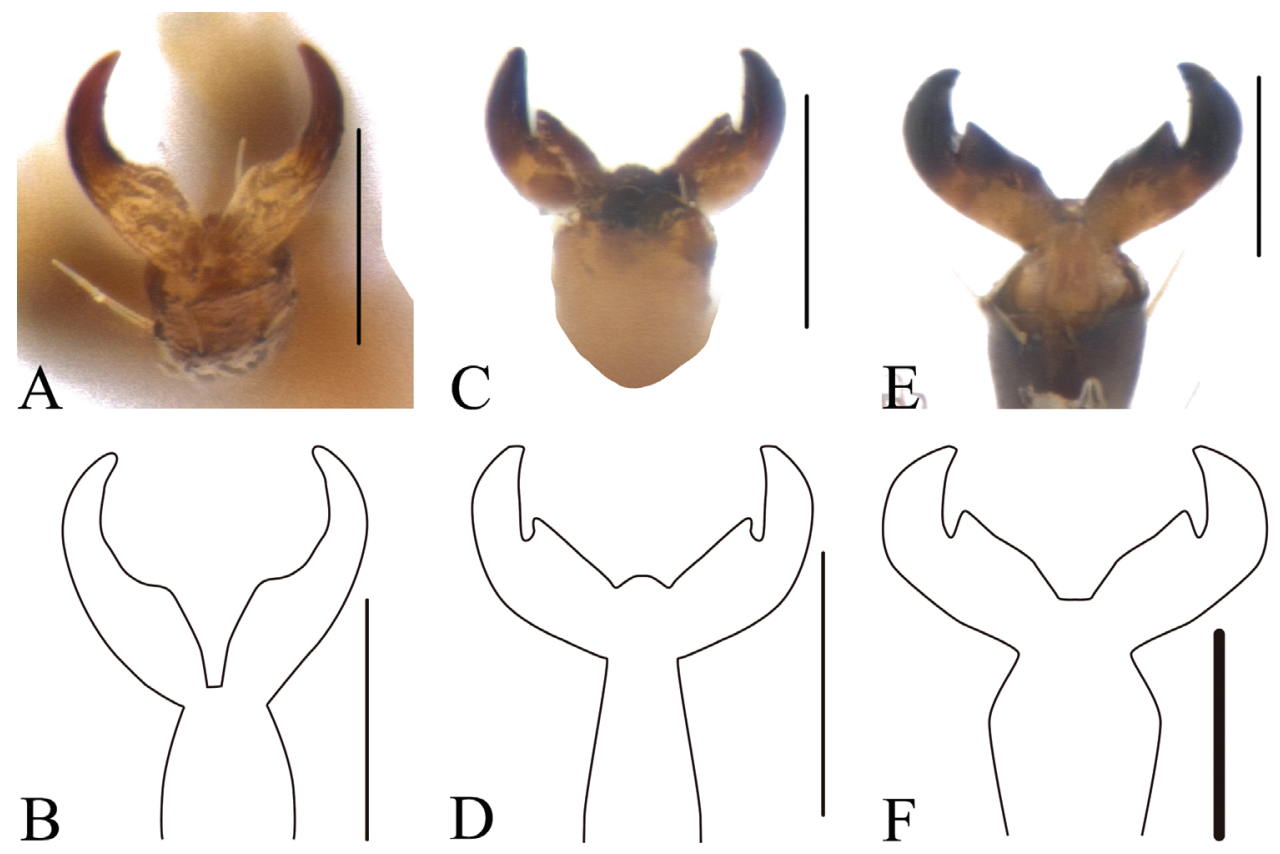

Figure 2. Melixanthus claws A, B M. menglaensis Duan, Wang \& Zhou, sp. nov. C, D M. similibimaculicollis Duan, Wang \& Zhou, sp. nov. E, F M. bimaculicollis Baly, 1865. Scale bars: $0.1 \mathrm{~mm}$.

out into a pair of small denticles. Mesosternum trapeziform, twice as wide as long. Metasternum wrinkled at sutural region and with dense pubescence. Pygidium flat, punctate and pubescent. Claws (Fig. 2A, B) not toothed, thickened basally.

Aedeagus (Figs 4A-C, 5A-C) elongate, about 3.2 times as long as wide, clubbed. Apex of median lobe narrower than middle, acute at apex, slightly curved in lateral view; with several pubescence on each side of apex and upper lateral margins, punctate on ventral side of upper middle part. Median orifice with middle sclerite bending inwards above surface. Upper part of median lobe with a pair of sclerotized prominence, exceeding the median lobe. Inner sac rather narrow, arrow-shaped. Tegmen Y-shaped, weakly sclerotized, almost translucent.

Female. Body more robust than male; spermatheca (Figs 4D, 5D) hook-shaped, bent in a right-angle halfway, slightly acute at apex; duct weakly sclerotized, irregularly coiling 9-12 times. Rectal sclerites (Fig. 4E) weakly sclerotized, slightly connected between two rectangular sclerites on ventral side.

Distribution. China (Yunnan); Vietnam (Tonkin).

Etymology. The specific epithet is derived from the name (Pinyin) of the type locality, Mengla.

Diagnosis. This species is similar to M. bimaculicollis Baly, 1865 , but can be distinguished from that species in having finer punctures on the head, a narrower pronotum, an impunctate scutellum, and fine puncture rows on the elytra, whereas M. bimaculicollis has the elytra with distinct punctures and a surrounded by dark ring; 

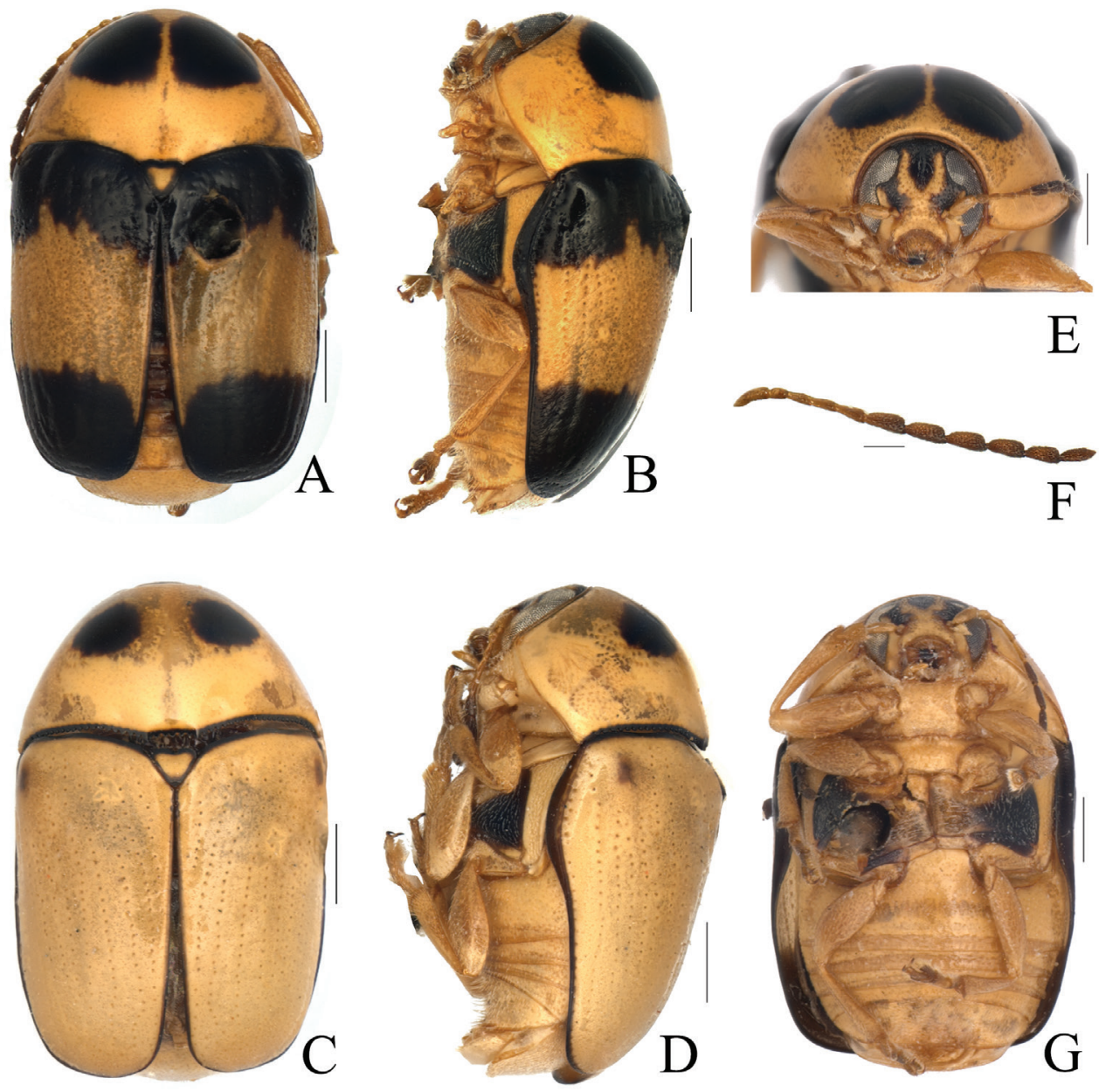

Figure 3. Melixanthus menglaensis Duan, Wang \& Zhou, sp. nov. A, C habitus B, D lateral view of habitus $\mathbf{E}$ head $\mathbf{F}$ antennae $\mathbf{G}$ ventral view of habitus. Scale bars: $0.5 \mathrm{~mm}(\mathbf{A}-\mathbf{E}, \mathbf{G}), 0.2 \mathrm{~mm}(\mathbf{F})$.

its claws are not toothed (Fig. 2A, B) and the basal margin of its prosternum is drawn out into a pair of small, sharp denticles (Fig. 1A, B).

Melixanthus similibimaculicollis Duan, Wang \& Zhou, sp. nov.

http://zoobank.org/CF48CD44-29B9-4CCA-BB5F-764FA5F15982

Figures 1, 2, 6, 7

Type locality. China: Yunnan Province: Cheli.

Type material examined. Holotype: male, China: Yunnan Province: Cheli, 9.III.1957, coll. Fuji Pu (IZ-CAS); Paratypes: China: Yunnan Province: 1 male, 


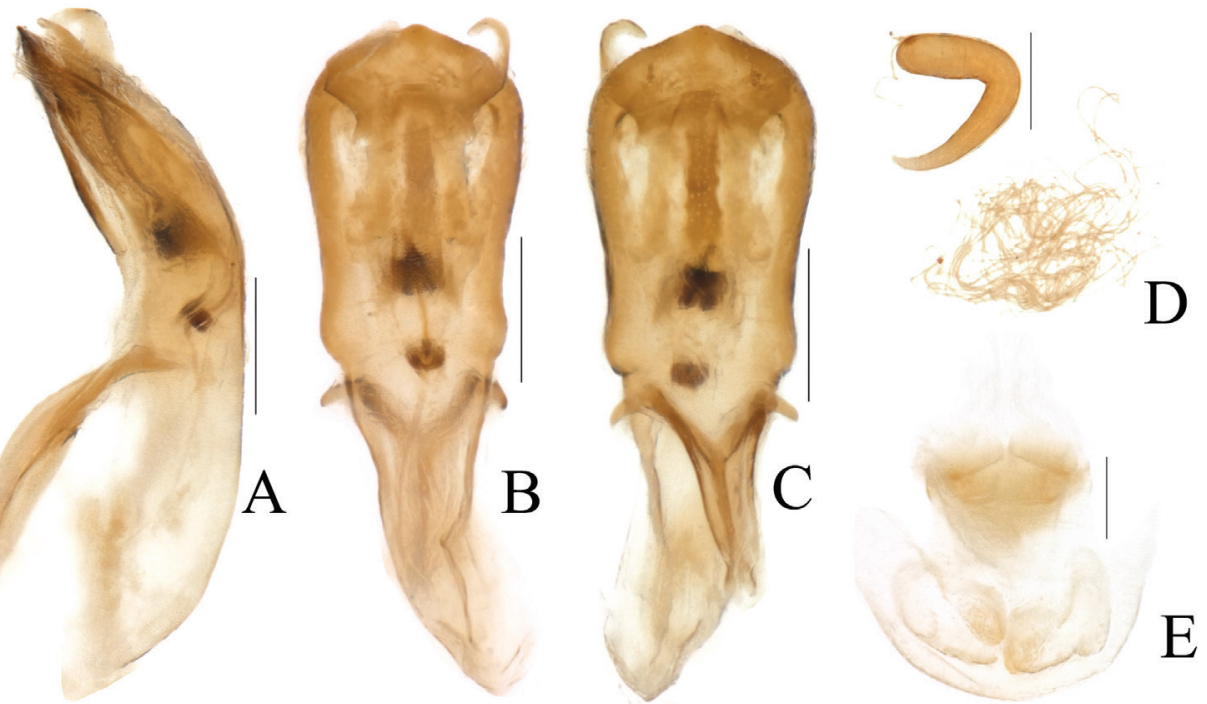

Figure 4. Melixanthus menglaensis Duan, Wang \& Zhou, sp. nov. A lateral view of aedeagus B dorsal view of aedeagus $\mathbf{C}$ ventral view of aedeagus $\mathbf{D}$ spermatheca $\mathbf{E}$ female rectal pad. Scale bars: $0.2 \mathrm{~mm}$.
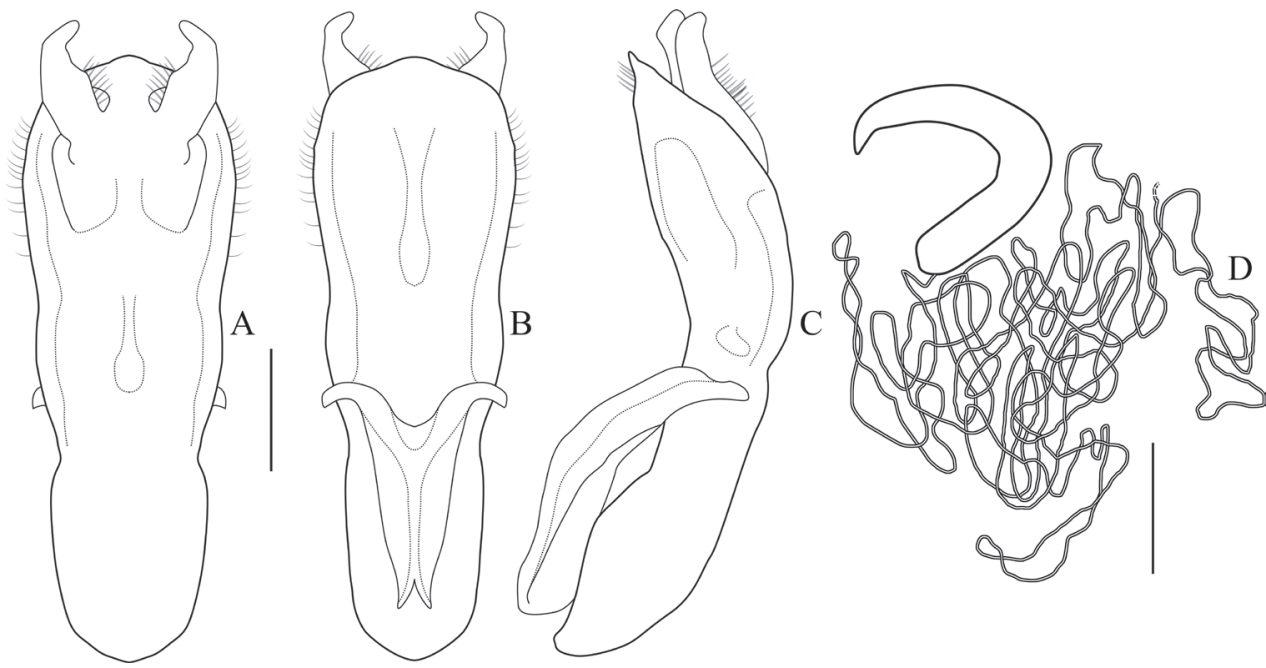

Figure 5. Melixanthus menglaensis Duan, Wang \& Zhou, sp. nov. A dorsal view of aedeagus B ventral view of aedeagus $\mathbf{C}$ lateral view of aedeagus $\mathbf{D}$ spermatheca. Scale bars: $0.2 \mathrm{~mm}$.

$50 \mathrm{~km}$ southwest of Mojiang, 30.III.1955, coll. Kryzhanowski (IZ-CAS); 1 female, Longling, 1600 m, 20.V.1955, coll. Kryzhanowski (IZ-CAS).

Measurements. $\mathrm{BL}=2.55-2.82 \mathrm{~mm}, \mathrm{BW}=1.57-1.73 \mathrm{~mm}, \mathrm{HL}=0.82 \mathrm{~mm}$, $\mathrm{HW}=0.85 \mathrm{~mm}, \mathrm{PL}=0.90 \mathrm{~mm}, \mathrm{PW}=1.62 \mathrm{~mm}, \mathrm{EL}=1.81 \mathrm{~mm}, \mathrm{AL}=0.91 \mathrm{~mm}$, $\mathrm{AW}=0.34 \mathrm{~mm}, \mathrm{SW}=0.39 \mathrm{~mm}$. 

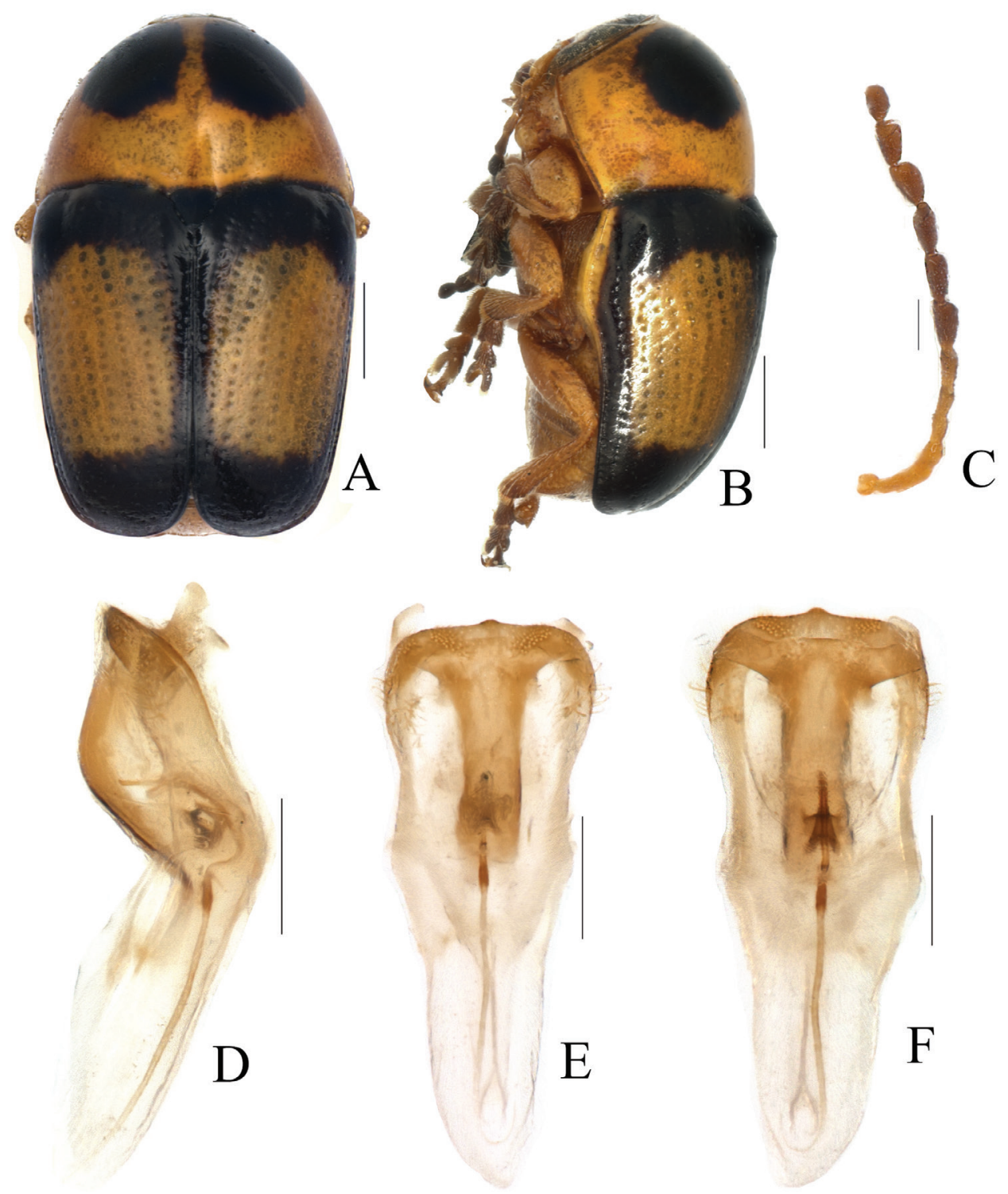

Figure 6. Melixanthus similibimaculicollis Duan, Wang \& Zhou, sp. nov. A habitus B lateral view of habitus $\mathbf{C}$ antennae $\mathbf{D}$ lateral view of aedeagus $\mathbf{E}$ ventral view of aedeagus $\mathbf{F}$ dorsal view of aedeagus. Scale bars: $0.5 \mathrm{~mm}(\mathbf{A}, \mathbf{B}), 0.2 \mathrm{~mm}(\mathbf{C}-\mathbf{F})$.

Description. Body (Fig. 6A, B) elongate, almost cylindrical, rounded anteriorly. Head yellow, vertex with a darkish brown triangular marking; antennae (Fig. 6C) with basal 5 segments yellowish brown, the rest brown; clypeus yellow; labrum yellowish brown; mandibles reddish brown. Pronotum yellow, and basal margin pitchy brown, forming 2 nearly round pitchy brown markings along anterior margin. Scutellum entirely black. Elytra pitchy black only in basal and apical parts, with a large yellow band 

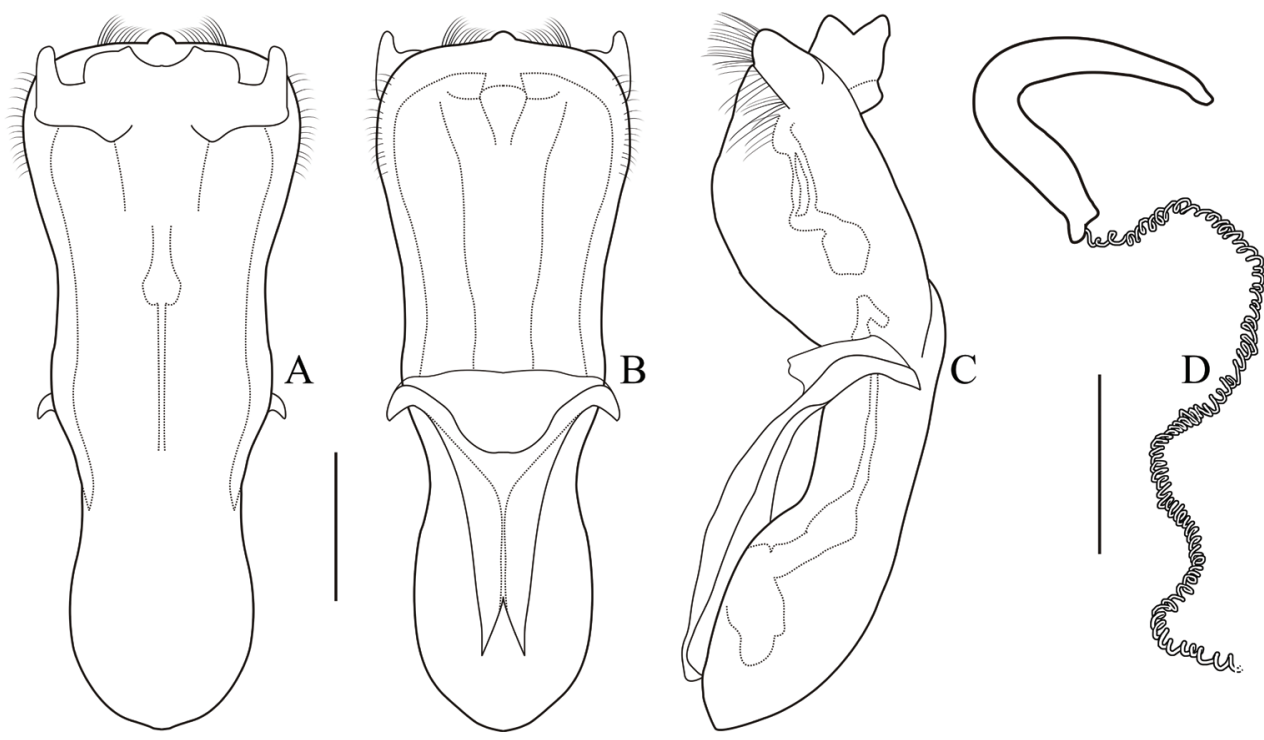

Figure 7. Melixanthus similibimaculicollis Duan, Wang \& Zhou, sp. nov. A dorsal view of aedeagus B ventral view of aedeagus $\mathbf{C}$ lateral view of aedeagus $\mathbf{D}$ spermatheca. Scale bars: $0.2 \mathrm{~mm}$.

in middle region, covering about $2 / 3$ of whole elytron; sutural and lateral margins also pitchy black. Ventral surface yellowish brown.

Head with sparsely pubescence, without punctures, flattened in midline, and with longitudinal shallow groove on frons. Eyes kidney-shaped, deeply emarginated; antennal insertions about equally separated with superior eye-lobes. Clypeus trapeziform, anterior margin concave, without punctures. Antennae (Fig. 6C) long and slightly thin, reaching $1 / 3$ region of elytra; $1^{\text {st }}$ segment clubbed; $2^{\text {nd }}$ oblong, about $1 / 2$ as long as $1^{\text {st }} ; 3^{\text {rd }}-5^{\text {th }}$ thin, about equal in length, longer than $2^{\text {nd }} ; 6$ apical segments moderately thickened, about 1.7-2.0 times as long as wide, last segment pointed apically.

Pronotum (Fig. 6A, B) 1.8 times as wide as long, moderately narrowed and rounded anteriorly; surface strongly convex, impunctate and shining. Scutellum triangular, nearly as long as wide, surface smooth, shining, apically elevated, observable in lateral view.

Elytra (Fig. 6A, B) with humeri prominent and glabrous, widest slightly behind humerus, feebly truncated at apex. Disc with regular rows of coarse punctures; interspace of rows without any punctures; epipleura slightly obliquely placed and observable in lateral view.

Ventral side smooth, partly clothed with pubescence. Prosternum (Fig. 1C, D) square, anterior margin nearly straight; basal margin slightly concave, and drawn out into a pair of small denticles. Mesosternum trapeziform, 1.5 times as wide as long. Metasternum with coarsely sporadic punctures in sutural region and with sparse pubescence. Pygidium flat, punctate and pubescent. Claws (Fig. 2C, D) distinctly toothed, thickened basally.

Aedeagus (Figs 6D-F, 7A-C) elongate, about 2.7 times as long as wide, clubbed. Anterior margin of median lobe nearly straight, middle part papillary protruding, strongly curved in lateral view; with several pubescence on each side of apex and upper 

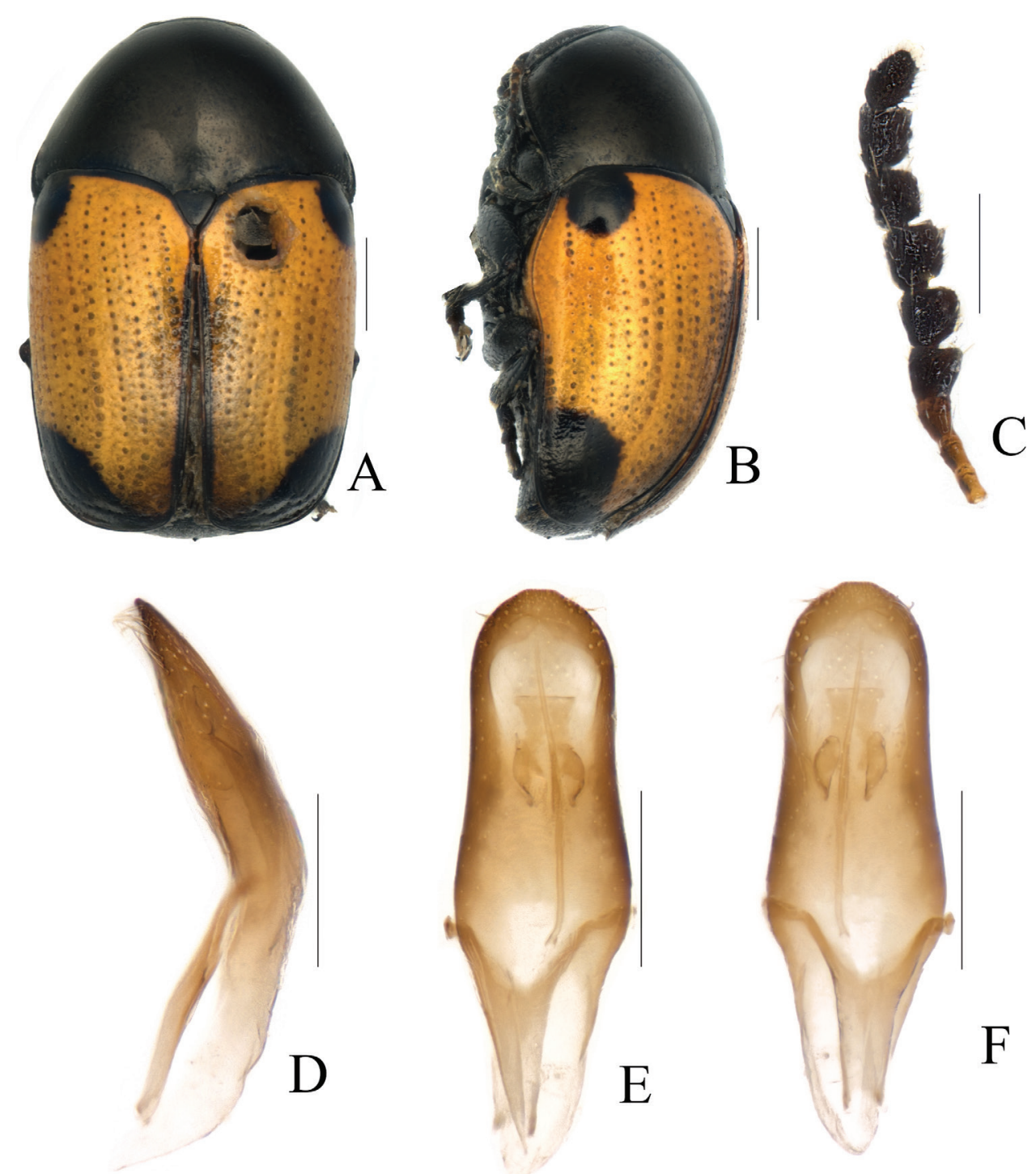

Figure 8. Melixanthus rufiventris Pic, 1926 A habitus B lateral view of habitus $\mathbf{C}$ antennae $\mathbf{D}$ lateral view of aedeagus $\mathbf{E}$ ventral view of aedeagus $\mathbf{F}$ dorsal view of aedeagus. Scale bars: $0.5 \mathrm{~mm}(\mathbf{A}, \mathbf{B}), 0.2 \mathrm{~mm}(\mathbf{C}-\mathbf{E})$.

lateral margins, punctate on apex of median lobe. Median orifice with middle sclerite bending inwards above surface. Upper part of median lobe with a pair of sclerotized prominence, exceeding the median lobe. Inner sac rather narrow, arrow-shaped. Tegmen Y-shaped, weakly sclerotized, almost translucent.

Female. Body more robust than male; spermatheca (Fig. 7D) hook-shaped, bent at a right-angle halfway, slightly acute at apex. Duct weakly sclerotized, tightly coiled. Rectal sclerites absent in specimen studied. 

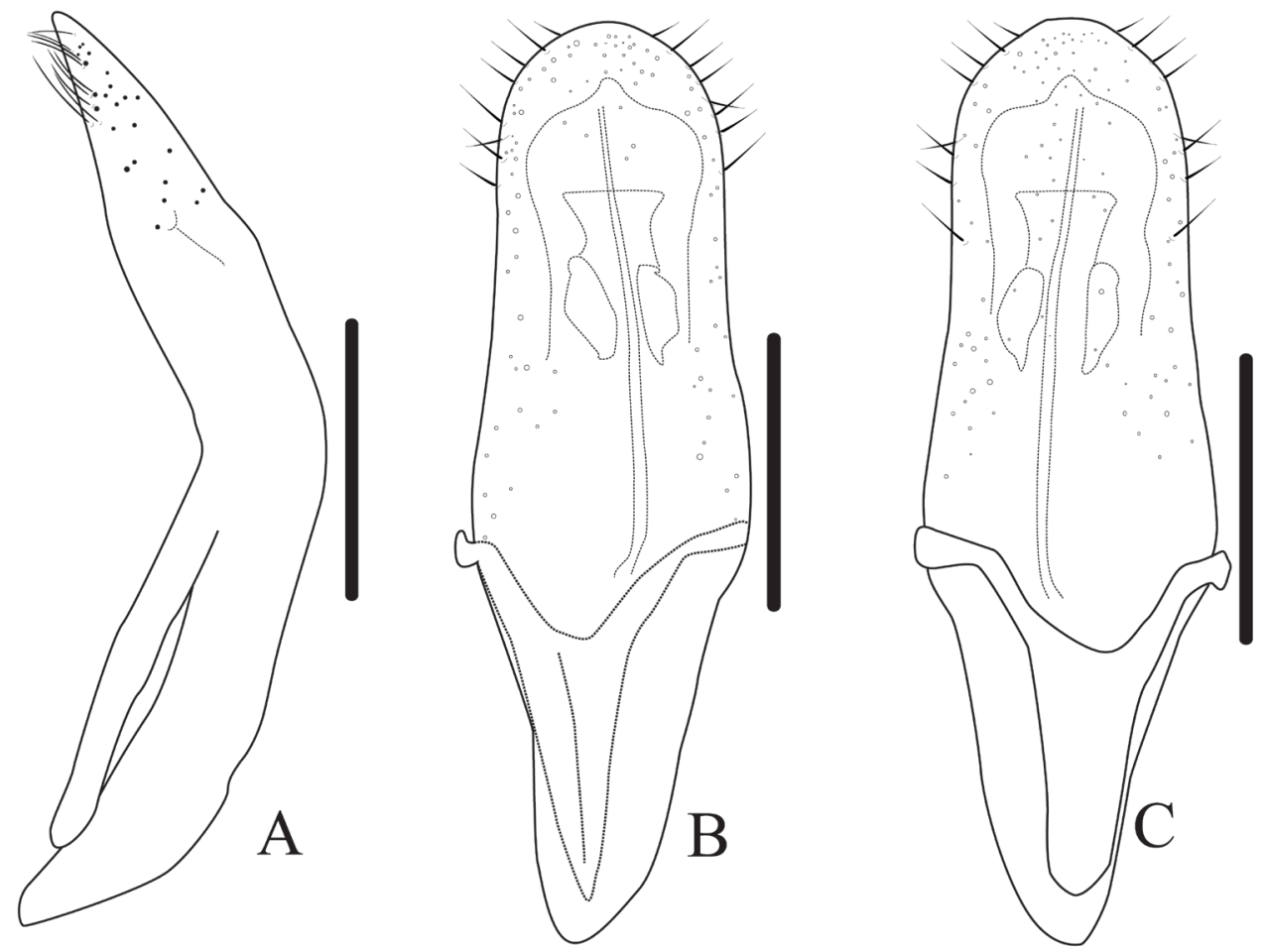

Figure 9. Melixanthus rufiventris Pic, 1926 A lateral view of aedeagus ventral view of aedeagus $\mathbf{C}$ dorsal view of aedeagus $\mathbf{D}$ spermatheca. Scale bars: $0.2 \mathrm{~mm}$.

Distribution. China (Yunnan).

Etymology. The specific epithet is derived from the Latin terms simili-, bi-, macu$l i$ - and collis, to indicate the new species near to $M$. bimaculicollis.

Diagnosis. The new species is similar to M. bimaculicollis Baly, 1865, but can be distinguished from it by the smaller body size; head and scutellum without any punctures; slightly narrower pronotum; elytra with finer punctures, and only basal part punctures surrounded by dark ring; basal margin of prosternum (Fig. 1C, D) drawn out into a pair of small sharp denticles. Melixanthus similibimaculicollis is also similar to M. menglaensis Duan, Wang \& Zhou, sp. nov., but can be distinguished by the following characters: head without punctures; claws toothed (Fig. 2C, D); and body size smaller.

\section{Melixanthus rufiventris Pic, 1926, new country record from China}

Figures 8, 9

Pic 1926: 11 (type locality: Tonkin); Kimoto and Gressitt 1981: 333 (Vietnam); Medvedev 2012: 163. 
Material examined. CHINA: Hunan province: 3 males, 6 females, Shimen country, Hupingshan town, Wangyue lake, $29.93222^{\circ} \mathrm{N}, 110.7776^{\circ} \mathrm{E}, 248 \mathrm{~m}, 11 . \mathrm{X} .2014$, coll. Jian Yao (IZ-CAS).

Measurements. $\mathrm{BL}=2.65-2.93 \mathrm{~mm}, \mathrm{BW}=1.64-1.80 \mathrm{~mm}, \mathrm{HL}=0.75 \mathrm{~mm}$, $\mathrm{HW}=0.80 \mathrm{~mm}, \mathrm{PL}=0.92 \mathrm{~mm}, \mathrm{PW}=1.73 \mathrm{~mm}, \mathrm{EL}=1.92 \mathrm{~mm}, \mathrm{AL}=0.64 \mathrm{~mm}$, $\mathrm{AW}=0.20 \mathrm{~mm}$.

Distribution. China (Hunan); Vietnam.

\section{Acknowledgements}

We thank the editors and the anonymous reviewers for their valuable suggestions. This study was supported in part by the Ministry of Ecology and Environment, China (no. 2019HJ2096001006) and by the Ministry of Science and Technology of China (2015FY210300). Insect Diversity Observation Network of Sino BON (CAS, China) provided assistances with field investigations. We also want to thank Ms Liang Su (Beijing, China) for her help in preparing some line drawing plates.

\section{References}

Baly JS (1865) Phytophaga Malayana. A revision of the phytophagous beetles of the Malay Archipelago, with descriptions of the new species collected by Mr. A.R. Wallace. The Transactions of the Entomological Society of London (Series 3) 4: 1-76. [pls 1-5]

Chapuis F (1874) Famille des Phytophages. In: Lacordaire T, Chapuis F (Eds) Histoire naturelle des Insectes. Genera des coléopteres ou exposé méthodique et critique de tous les genres proposés jusqu'ici dans cet ordre d'insectes. Tome dixieme. Roret, Paris, 1-455.

Chûjô M (1954) A taxonomic study on the Chrysomelidae (Insecta-Coleoptera) from Formosa. Part VII, subfamily Cryptocephalinae. Quarterly Journal of the Taiwan Museum 7: $137-248$.

Clavareau H (1913) Coleopterorum Catalogus. Auspiciis et auxilio W. Junk editus a S. Schenkling. Pars 53: Chrysomelidae: 5. Megascelinae, 6. Magalopodinae, 7. Clytrinae, 8. Cryptocephalinae, 9. Chlamydinae, 10. Lamprosominae. Berlin, 278 pp.

Gressitt JL (1942) Plant-beetles from south and west China. III. Clytrinae, Cryptocephalinae and Chlamydinae. Lingnan Science Journal 20: 325-376. [pls 19-22]

Gressitt JL, Kimoto S (1961) The Chrysomelidae (Coleopt.) of China and Korea, part 1. Pacific Insects Monograph 1A: 1-299.

Jacoby M (1908) The Fauna of British India, including Ceylon and Burma. Coleoptera, Chrysomelidae. Vol. 1. Taylor \& Francis, London, 534 pp.

Kimoto S, Gressitt JL (1981) Chrysomelidae (Coleoptera) of Thailand, Cambodia, Laos and Vietnam. 2. Clytrinae, Cryptocephalinae and Chlamisinae, Lamprosomatinae and Chrysomelinae. Pacific Insects 23: 329-333. 
Lopatin IK (2005) New species of leaf-beetles (Coleoptera, Chrysomelidae) from China. V. Entomologicheskoe Obozrenie 84: 873-880.

Medvedev LN (2012) To the knowledge of Oriental species of Melixanthus Suffrian, 1854 (Chrysomelidae: Cryptocephalinae). Entomologische Zeitschrift 122(4): 162-170.

Pic M (1926) Nouveautés diverses. Mélanges Exotico-Entomologiques 47: 1-32.

Schöller M, Löbl L, Lopatin IK (2010) Chrysomelidae: Cryptocephalinae: remaining Cryptocephalini. In Löbl I, Smetana A (Eds). Catalogue of Palaearctic Coleoptera, Vol. 6. Chrysomeloidea. Apollo Books, Stenstrup, 606-617.

Tan JJ (1988) Coleoptera: Eumolpidae. In: Huang FS, Wang PY, Yin WY, Yu PY, Lee TS, Yang CK, Wang XJ (Eds) Insects in Mt. Namjagbarwa region of Xizang. Science Press, Beijing, 309-333.

Tan JJ, Yu PY, Li HX, Wang SY, Jiang SQ (1980) Economic Insect Fauna of China Fasc. 18 Coleoptera: Chrysomeloidea (I). Science Press, Beijing, [xiii +] 213 pp.

Tan JJ, Pu FJ (1992) Two new species of the genus Melixanthus Suffrian from Hengduan Mountains, China (Coleoptera: Eumolpidae: Cryptocephalinae). In: Chen SX (Ed.) Insects in Hengduan Mountains region. Vol. 1. Science Press, Beijing, 754-829.

Suffrian E (1854) Verzeichniss der bis jetzt bekannt gewordenen Asiatischen Cryptocephalen. Linnaea Entomologica 9: 1-169.

Weise J (1895) Zwei neue Cryptocephalinen-Gattungen. Deutsche Entomologische Zeitschrift 1895: 57-58. https://doi.org/10.1002/mmnd.48018950112 